\title{
Analysis of shear transfer and gap opening in timber- concrete composite members with notched connections
}

\author{
Lorenzo Boccadoro $・$ René Steiger $\cdot$ Simon Zweidler $\cdot$ Andrea Frangi $\mathbb{B}$
}

Received: 30 June 2017 / Accepted: 19 September 2017/Published online: 7 October 2017

(C) RILEM 2017

\begin{abstract}
In timber-concrete composite members with notched connections, the notches act as the shear connections between the timber and the concrete part, and have to carry the shear flow necessary for composite action. The shear transfer through the notches generates shear and tensile stresses in both parts of the composite member, which may lead to brittle failure and to an abrupt collapse of the structure. Although simplified design formulas already exist, some structural aspects are still not clear, and a reliable design model is missing. This paper summarizes current design approaches and presents analytical models to understand the shear-carrying mechanism,
\end{abstract}

L. Boccadoro · A. Frangi $(\bowtie)$

Institute of Structural Engineering - Timber Structures, ETH Zurich, Stefano-Franscini-Platz 5, 8093 Zurich,

Switzerland

e-mail: frangi@ibk.baug.ethz.ch

L. Boccadoro

e-mail: boccadoro@ibk.baug.ethz.ch

\section{R. Steiger}

Empa Swiss Federal Laboratories for Materials Science and Technology, Ueberlandstrasse 129, 8600 Dübendorf, Switzerland

e-mail: rene.steiger@empa.ch

\section{S. Zweidler}

Institute of Structural Engineering - Concrete Structures and Bridge Design, ETH Zurich, Stefano-Franscini-Platz 5, 8093 Zurich, Switzerland e-mail: zweidler@ibk.baug.ethz.ch to estimate the shear stresses acting in the timber and concrete, and to predict failure. The analysis concentrates on three problems: the shearing-off failure of the timber close to the notch, the shear failure of the concrete, and the influence of the shear flow on the gap opening between the timber and concrete. Parts of the model calculations could be compared to experimental observations. The conclusions of this paper contribute to improving current design approaches.

Keywords Timber-concrete composite $\cdot$ Notched connection - Shear failure - Shearing-off failure · Gap opening

\section{Introduction}

Timber-concrete composite structures represent a convenient solution to refurbish old buildings and for new construction because they are able to offer several structural, economic and ecological advantages compared to reinforced concrete slabs and timber slabs [1]. In a timber-concrete composite member, the timber part is usually subjected to tension and the concrete part to compression. To ensure composite action, a shear connection between the two parts is needed. As shear connections markedly influence the structural behavior of the composite member, several research projects have focused on 
developing connection systems (e.g. screws [2], or notches cut from timber [3, 4]).

Notches represent easy to fabricate and hence, competitive timber-concrete connections. Notches act as shear keys. They minimize the relative displacement between the timber and concrete [3], and hence, they ensure a higher stiffness and a more efficient composite action than most of the other connection systems. However, a notch causes a reduction in timber cross-section. Furthermore, a notched connection implies shear-carrying mechanisms in both parts of the composite member, which may lead to critical stress states and brittle failure modes that should be prevented by means of appropriate design. The present paper focuses on this topic.

The shear-carrying mechanism plays an important role in the structural behavior of timber-concrete composite members with notched connections. Composite action is ensured by a shear flow between the timber and the concrete part, which is carried by the notches. In addition, various shear-carrying mechanisms develop within the two parts of the composite member. The stresses generated by these shearcarrying mechanisms may cause brittle failure modes (Fig. 1):

- flexural-shear failure of the concrete

- shearing-off failure of the timber close to the notch

- shear failure of the timber part

- gap opening
These failure modes were observed in several experimental research studies on timber-concrete notched connections (e.g. [4-7]). Since such failure modes may lead to a sudden collapse of the composite member, the designer should be made able to predict them by providing him with reliable models. Although simplified design formulas already exist, several issues are still subject of discussion.

The most frequent questions relate to the shearcarrying mechanism in the concrete. In contrast to conventional reinforced concrete structures, where extensive studies on the shear behavior were conducted (e.g. [8]), in timber-concrete composite structures with notched connections, this topic needs further research. On the basis of truss models, some authors (e.g. [9]) suggested to equip the composite members with screws to ensure the shear transfer and to prevent gap opening. However, in practice, there is no general agreement in the method to design such fasteners. Further critical topics related to shear are the stress distribution in the timber close to the notch edges, the design approach to prevent brittle shearingoff failure of the timber, and the relationship between shear forces at the interface and gap opening.

This paper will present equilibrium-based analytical methods to model the shear-carrying mechanism in timber-concrete composite members with notched connections and will discuss criteria to prevent brittle failure modes due to shear. The conclusions from this analysis are compared to experimental observations.

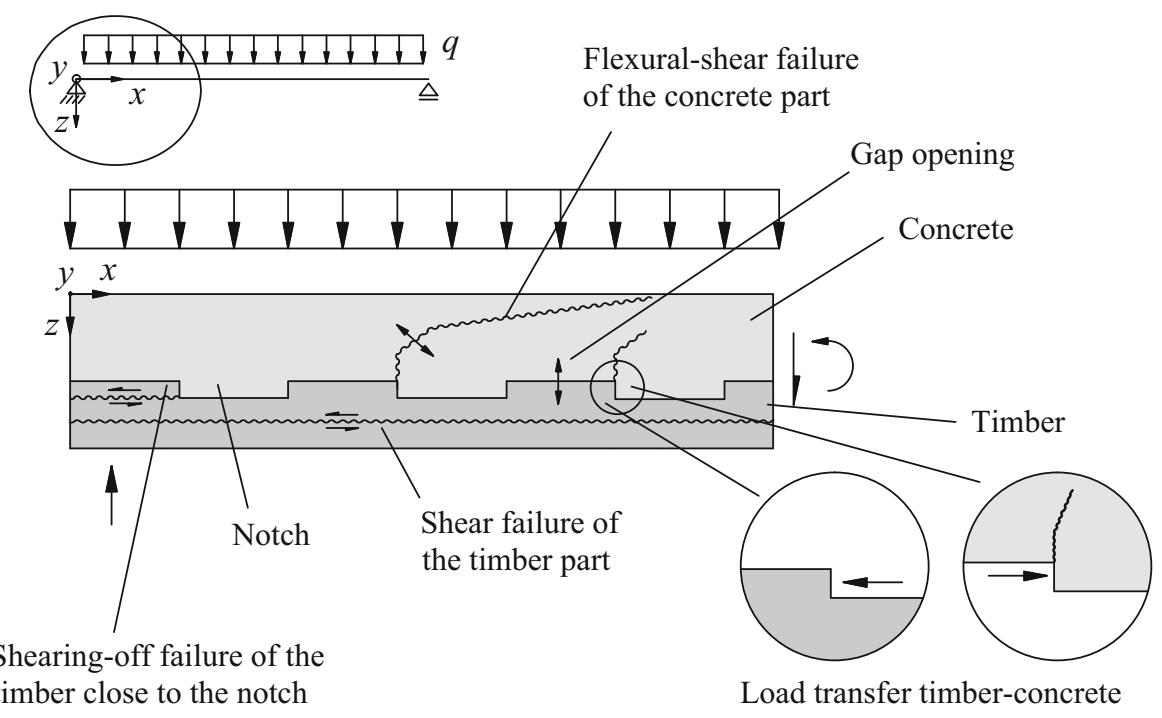

Fig. 1 Possible shear failure modes and gap opening in a timber-concrete composite member with a notched connection 


\section{Load-carrying mechanism}

This section presents an analytical approach to understand the shear-carrying mechanism in a timber-concrete composite member with a notched connection and to estimate the shear forces.

Figure 2a shows a timber-concrete composite member as one-span beam and subjected to four-point bending as an example. Figure $2 b$ shows the composite cross-section and the axial stresses and strains in

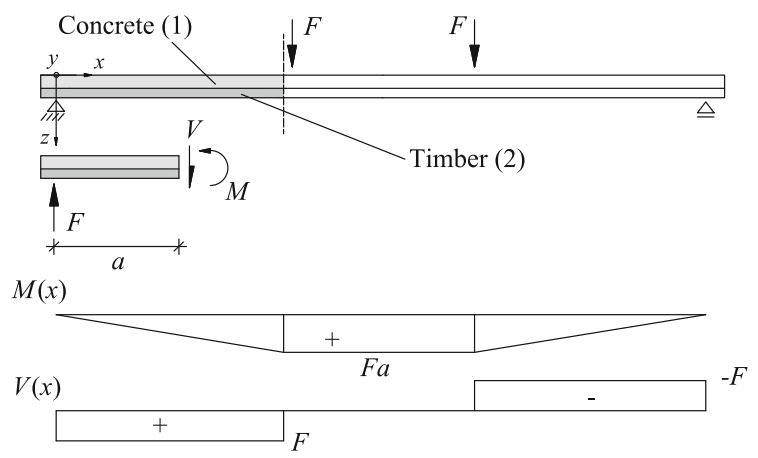

(a)

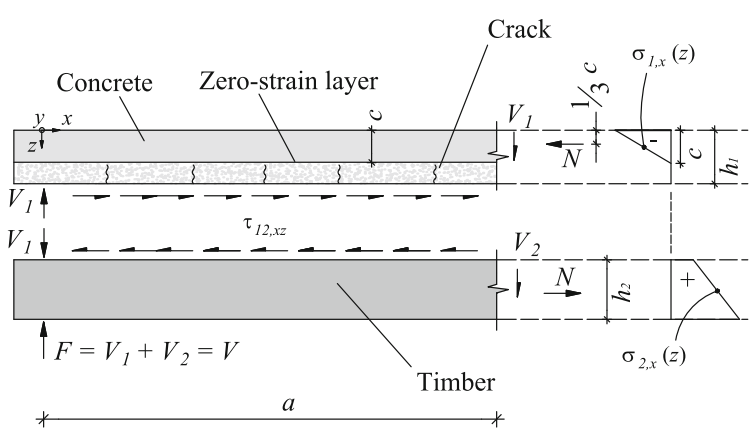

(c)

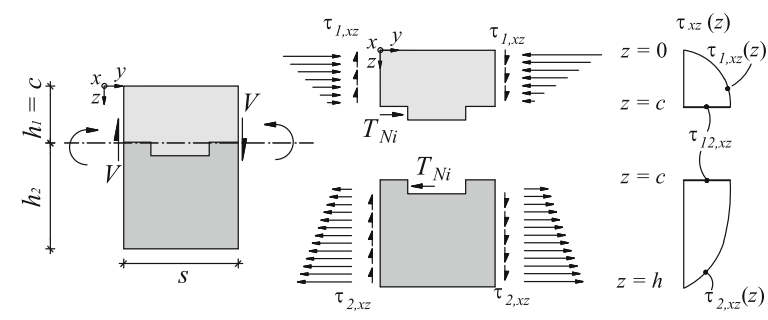

(e)

Fig. 2 Load-carrying mechanism in a timber-concrete composite member subjected to four-point bending where the zero strain layer is located in the concrete part: a static system; b composite cross-section with axial stresses and strains; c internal forces and stresses in the case of a glued connection; the case that the zero-strain layer is located in the concrete. The reason for this choice is that the models presented in this paper were developed in the frame of a research project about timber-concrete composite members made of $40 \mathrm{~mm}$ thick beech LVL plates and $160 \mathrm{~mm}$ thick concrete layers, where the zero-strain layer was located in the concrete [10]. Nevertheless, the presented approach allows to derive similar models for the case where the zero-strain layer is located in the timber too.

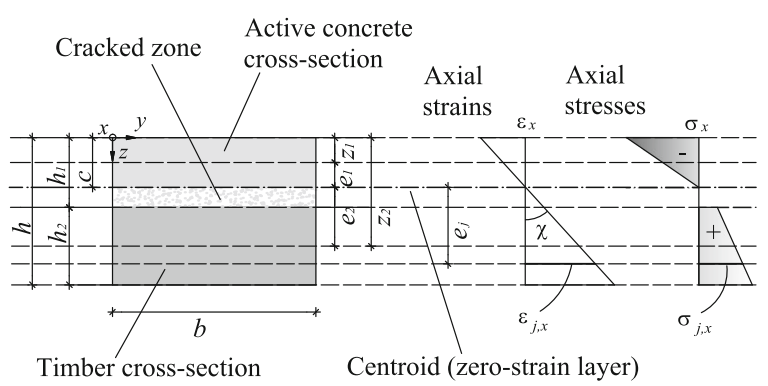

(b)

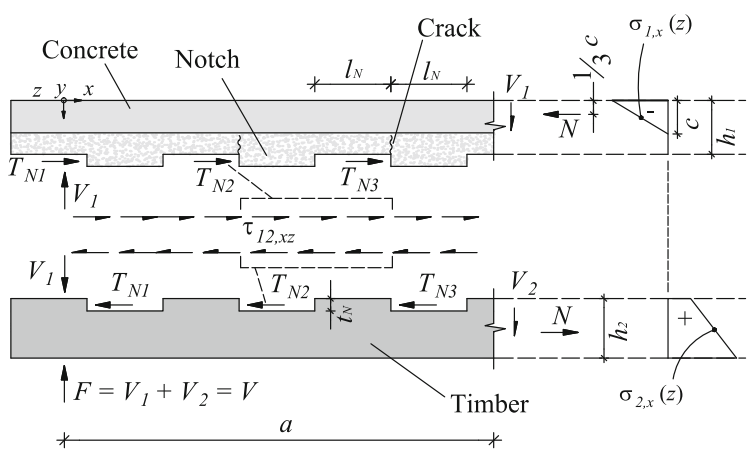

(d)

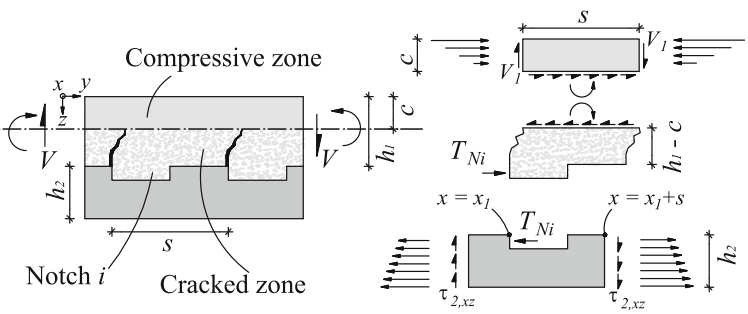

(f)

d internal forces and stresses in the case of a notched connection; e vertical shear stress when the centroid of the composite cross-section coincides with the interface; $\mathbf{f}$ vertical shear stress when the centroid of the composite cross-section is in the concrete 
The timber part is subjected to tension and bending, and the concrete layer carries compression and bending. As shown in Fig. 2c, if the timber and concrete are glued together, the shear flow at the interface $\tau_{12, x z}$ is distributed over its area. In contrast, if the shear connection is accomplished by means of notches cut in the timber part of the composite member, the shear flow between the timber and concrete is transferred through compression over the notch edges (Fig. 2d).

If the two parts of the composite member and the shear connection behave elastically, the stresses can be calculated with the established calculation methods for composite cross-sections ( $n$-method for rigid shear connection and $\gamma$-method for flexible shear connection) $[6,11-13]$. These methods are based on the following assumptions:

- The two parts of the cross-section behave linearelastic.

- The behavior of the shear connections are linearelastic.

- The distribution of the axial strains is linear in each part of the cross-section.

- The parts of the cross-section are perpendicular to the axis of the deformed beam.

- No gap opening and no vertical stresses at the interface occur. Thus, the timber and concrete bend with the same deflection and the same curvature.

Since the tensile strength of concrete is very small, it is assumed that the part of the concrete under tension is cracked and does not carry tensile stresses. Hence, the effective concrete cross-section has a reduced thickness. Since both notched and glued connection have high stiffnesses, the stresses can be calculated under the assumption of a fully rigid connection [11], and the calculation method for composite crosssections with rigid connections (also called $n$-method [13]) can be applied. For notched connections with geometries or materials different from those evaluated in this study, the assumption of a full rigid connection should be checked. The following formulas refer to the case illustrated in Fig. 2b, where the zero-strain layer is located in the concrete. The $n$-value of the part $i$ is obtained by dividing the modulus of elasticity of the part $i$ by a freely selectable reference modulus of elasticity $E$ [13]:
$n_{i}=\frac{E_{i}}{E}$

The centroid of the composite cross-section (which corresponds to the zero strain layer) is [13]:

$c=\frac{\sum E_{i} A_{i} z_{i}}{\sum E_{i} A_{i}}=\frac{\sum n_{i} A_{i} z_{i}}{\sum n_{i} A_{i}}$

where $A_{i}$ is the area of the effective cross-section of part $i$ and $z_{i}$ is $z$-coordinate of its centroid measured from the top.

The effective moment of inertia $I_{\text {ef }}$ of the composite cross-section is [13]:

$I_{\mathrm{ef}}=\sum n_{i} I_{i}+\sum n_{i} A_{i} e_{i}^{2}$

where $I_{1}=c^{3} b / 12$ and $I_{2}=h_{2}^{3} b / 12$.

The strain $\varepsilon_{j, x}$ at point $j$ located in part $i$ is obtained by multiplying the curvature of the composite crosssection $M / E I_{\text {ef }}$ by the distance $e_{j}$ between the centroid of the composite cross-section and the point $j$ (Fig. 2b). The corresponding axial stress $\sigma_{j, x}$ can be calculated by multiplying the axial strain $\varepsilon_{j, x}$ by the elasticity modulus $E_{i}$ of the material considered [13]:

$\sigma_{j, x}=\varepsilon_{j, x} E_{i}=\frac{M}{E I_{\mathrm{ef}}} e_{j} E_{i}=\frac{M}{I_{\mathrm{ef}}} e_{j} n_{i}$

As shown in Fig. 2b, according to this model, the axial strains in the two parts of the composite member follow the same gradient because it is assumed that the two parts of the composite member bend with the same curvature. In contrast, the gradient of the axial stresses depends on the stiffness of the cross-section part.

The static moment for the calculation of the shear stress acting at the interface is:

$S_{12}=n_{1} A_{1} e_{1}=n_{2} A_{2} e_{2}$

The elastic shear stress at the interface between the two parts of the composite member can be calculated as:

$\tau_{12, x z}(x)=\frac{V(x) S_{12}}{I_{\mathrm{ef}} \cdot b}$

In the case of a glued connection, $\tau_{12, x z}(x)$ corresponds to the shear stress in the glue layer. In contrast, if the connection is accomplished by means of notches, it can be assumed that the notches between the support and the point $x=a$ carry the integral of the elastic shear stress $\tau_{12, x z}(x)$ at the interface (Fig. 2c, d): 


$$
\sum_{i=1}^{5} T_{\mathrm{Ni}}=b \cdot \int_{0}^{a} \tau_{12, x z}(x) \mathrm{d} x
$$

As shown in Fig. 2c, d, the resulting compressive axial force in the concrete and tensile force in the timber at a distance $a$ from the support are named $N$, correspond to the integral of the axial stresses $\sigma_{1, x}$ and $\sigma_{2, x}$ over the effective cross-sections, and act in the centroids of the axial stress distributions. Furthermore, the resulting axial force at $x=a$ is equal to the integral of the theoretic elastic shear stress at the interface between $x=0$ and $x=a$. This condition can be summarized as follows:

$$
\begin{aligned}
N & =-b \int_{0}^{c} \sigma_{1, x}(z) \mathrm{d} z=b \int_{h_{1}}^{h} \sigma_{2, x}(z) \mathrm{d} z \\
& =b \int_{0}^{a} \tau_{12, x z}(x) \mathrm{d} x=F \frac{a n_{1} b c^{2}}{2 I_{\mathrm{ef}}}
\end{aligned}
$$

Under the assumption that the notches carry the integral of $\tau_{12, x z}(x)$, it can be interpreted that the sum of the notch forces $T_{\mathrm{Ni}}$ between $x=0$ and $x=a$ is equal to the resulting axial force $N$ at $x=a$.

If the connections are ductile (e.g. ductile steel fasteners or notches designed to fail due to plastic timber compressive deformations) and have an adequate deformation capacity, they can redistribute the shear forces. This means that, in a one-span beam, the maximal axial force in the parts of the composite member is equal to the sum of the shear resistance of the connectors between the support and the critical cross-section [11]. If the connections may exhibit elastic-brittle behaviour, this assumption is not valid.

As previously assessed, due to equilibrium, the parts of the composite cross-section carry vertical shear stresses too. The shear stress $\tau_{2, x z}(z)$ acting in the timber part of the composite cross-section can be described by means of the following equation:

$\tau_{2, x z}(z)=\frac{V \cdot S_{2}(z)}{b \cdot I_{\mathrm{ef}}}=\frac{V}{I_{\mathrm{ef}}} \cdot n_{2} \cdot(h-z) \cdot\left(\frac{z}{2}+\frac{h}{2}-c\right)$

This stress distribution is parabolic and has a maximum close to $z=h_{1}$. The total amount of shear force carried by the timber part of the cross-section can be calculated as follows:

$$
\begin{aligned}
V_{2} & =b \cdot \int_{h_{1}}^{h} \tau_{2, x z}(z) \mathrm{d} z \\
& =\frac{b \cdot V \cdot n_{2}}{I_{\text {ef }}}\left(\frac{h^{3}}{3}-\frac{h_{1} h^{2}}{2}+c \cdot h_{1} h+\frac{h_{1}^{3}}{6}-\frac{h_{1}^{2} c}{2}\right)
\end{aligned}
$$

In the case that the zero-strain layer coincides with the interface (Fig. 2e), the shear stress in the concrete $\tau_{1, x z}(z)$ and the corresponding shear force $V_{1}$ can be estimated with the same approach, and the total shear force $V$ acting on the composite cross-section is equal to $V_{1}+V_{2}$. If the zero-strain layer is in the timber, similar formulas can be derived.

However, if the zero-strain layer is located in the concrete part of the composite member, cracks cause discontinuities, and the concrete develops a cantilever action (Fig. 2f). The first method to estimate the shear force acting on the effective concrete cross-section is to subtract the shear force carried by the timber part of the cross-section from the total shear force:

$$
V_{1}=V-V_{2}=V-b \cdot \int_{h_{1}}^{h} \tau_{2, x z}(z) \mathrm{d} z
$$

where $\tau_{2, x z}(z)$ is the shear stress in the timber according to Eq. 9. Alternatively, $V_{1}$ ca be calculated from the equilibrium condition of the concrete layer:

$$
V_{1}=T_{\mathrm{Ni}} \cdot \frac{h_{1}-c / 3}{s}=b \cdot \int_{x_{1}}^{x_{1}+s} \tau_{12, x z}(x) \mathrm{d} x \cdot \frac{h_{1}-c / 3}{s}
$$

where $\tau_{12, x z}(x)$ is the theoretic elastic shear stress at the interface calculated according to Eq. 6.

\section{Shearing-off failure of the timber}

In a timber-concrete composite member with a notched connection subjected to positive bending moment, the shear force, which occurs between the two parts, is transferred through the notch edges. Similar to step joints, this causes local shear and tensile stresses in the timber next to the notch edge (Fig. 3), which may lead to shearing-off failure. As observed in several tests (e.g. [4, 7, 14]), this failure mode is characterized by a sudden detachment of a timber piece next to the notch, and usually causes collapse of the composite member. 


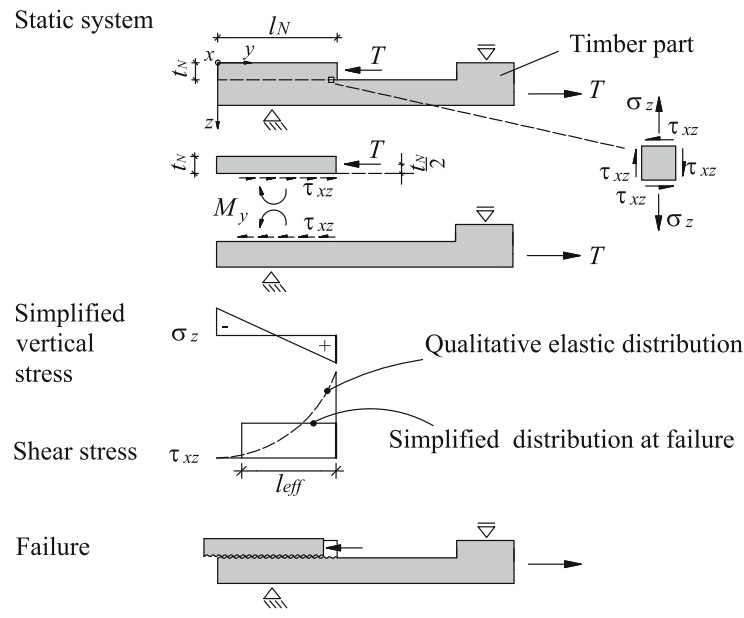

Fig. 3 Shearing-off failure of the timber part of the crosssection

In this section, several approaches to predict shearing-off failure of the timber are presented. Figure 3 shows a simplified model of a notch subjected to the force $T$. It is assumed that the shear stress $\tau_{x z}$ is transferred through a shear area located at a depth of $z=t_{N}$. In addition, the shear area is subjected to a tensile stress $\sigma_{z}$ generated by the eccentricity between the shear plane and the point where the notch force is transferred.

For load-carrying capacity design, as suggested by several authors (e.g. [7, 15, 16]) and as usually done in practice, the shear stress is assumed to be constant over a length of $l_{\text {eff }} \leq l_{N}$ and is estimated as follows:

$\tau_{x z}=\frac{T}{b \cdot l_{\mathrm{eff}}}$

An important question arising in this approach is: which effective length $l_{\text {eff }}$ should be assumed. According to the approach presented by Fonrobert [17], which is usually adopted in design of step joints [16], the shear stress is assumed to be evenly distributed over the length $l_{\text {eff }}=8 t_{N}$. Frangi [15] distributed the shear force over the full timber length available (i.e. $l_{N}$ ). Based on the results of bending tests, Schönborn [7] suggested to ensure a minimal timber length of $12.5 \cdot t_{N}$ next to the notch.

However, the assumption of a constant shear stress distribution is a rough approximation of reality. In elastic conditions, the shear stress distribution is nonlinear and shows a peak close to the notch edge $[4,7,16]$ (Fig. 3). In theory, this is valid for low stress only, where the material is still elastic. According to the fracture mechanics theories presented by Smith et al. [18], timber is a quasi-brittle material and hence activates complex energy dissipation mechanisms, which imply softening in the stress-strain relationship. Thus, if the shear force reaches a significant level, it can be supposed that the shear stresses redistribute along the shear area. Nevertheless, additional theoretic and experimental research is needed to identify how the different zones of the timber close to the notch participate to the shear-carrying mechanism at the ultimate limit state.

In addition to the shear stress, as assessed by Steurer [19], a vertical stress $\sigma_{z}$ occurs because of the vertical distance between the point of action of the notch force $T$ and the notch edge (Fig. 3). The tensile stress in the notch edge can be estimated as follows:

$\sigma_{z}=\frac{3 t_{N} \cdot T}{b \cdot l_{N}^{2}}$

This stress calculation is strongly simplified. A more exact assessment of the stress distribution needs additional investigations. Moreover, if a notch is located close to the support of the slab, depending on the notch position, the timber zone in front of the notch may be also subjected to compressive stress perpendicular to the shear area due to the transfer of the vertical load to the support. Since perpendicular compression has a beneficial influence on the shear strength of timber [19], neglecting the compressive stress leads to a design.

The interaction between shear and tensile stresses perpendicular to the shear plane is a critical issue in timber structures, because a tensile stress decreases the shear strength [20]. Hence, in respect of shearing-off failure, the critical element is located close to the notch edge because in this point the perpendicular tensile stress is maximal ( $x=l_{N}$ and $z=t_{N}$ according to Fig. 3). As summarized by Steiger and Gehri [20], several analytical and experimental studies allowed to develop models to quantify the influence of perpendicular stresses on the shear strength of timber. The first type of models base on fracture mechanics (e.g. [21]) and ask for the introduction of a critical stress intensity factor (fracture toughness), which depends on the test setup and the material. The second type of models belong to the stress-based strength approach. In engineering, this approach is usually preferred to 
fracture mechanics because the concepts of stress, strain and strength are well established in the current analysis techniques. The material strengths are usually determined in standard tests. Special attention should be paid to the shear strength, because it is strongly dependent on the volume of the test specimen and on the test configuration [22]. It is suggested to derive the shear strength of timber from tests performed with a static system and dimensions similar to the investigated structure.

A family of failure criteria, which belong to the stress-based strength approach, are the phenomenological strength criteria, which are usually represented by mathematical expressions describing a strength surface [23]. One phenomenological strength criterion, which aroused great interest in timber engineering, is the tensor polynomial model presented by Tsai and $\mathrm{Wu}$ [24]. This approach considers orthotropic materials such as wood, in which tensile and compressive strengths are different. Although, as shown by Van der Put [25, 26], the tensor polynomial model can be used to represent the failure surface of wood, several aspects of these models are still matter of discussion [23]. Thus, in structural engineering, a stress analysis made by means of this model should be interpreted carefully.

If it is assumed that the timber part of the composite member described in Fig. 3 can be treated as a twodimensional problem in the $x-z$-plane, the criterion for shearing-off failure can be derived from the tensor polynomial failure criterion formulated for a state of plane stresses presented in [23]. This assumption is justified, for instance, in the case of a laminated veneer lumber plate with the glue layers in the $x-y$-plane. As shown in Fig. 3, it is assumed that the critical element, located close to the notch edge, is subjected only to shear stress $\tau_{x z}$ and tensile stress $\sigma_{z}$. The relevant strengths are the compressive strength of the timber perpendicular to the grain $f_{c, 90}$, the tensile strength perpendicular to the grain $f_{t, 90}$, and the shear strength parallel to the grain $f_{v}$. The shear stress $\tau_{x z}$ which causes failure can be written as follows:

$\tau_{x z} \leq f_{v} \sqrt{1+\sigma_{z}\left(\frac{1}{f_{c, 90}}-\frac{1}{f_{t, 90}}\right)-\frac{\sigma_{z}^{2}}{f_{c, 90} f_{t, 90}}}$

Strength criteria for shear and perpendicular stress which do not belong to the phenomenological strength criteria were developed too. The formula presented by the Swiss Code SIA 265 [27] is based on an elliptic interaction between shear stress $\tau_{x z}$ and stress perpendicular to the shear plane $\sigma_{z}$, can be used for different wood species, and fits experimental data well [20]. It should be taken into account that this elliptical equation should be used only in the cases where shear is the predominant stress (i.e. for low levels of perpendicular tension or compression). The shear stress $\tau_{x z}$ which causes failure can be written as follows:

$$
\tau_{x z} \leq f_{v} \sqrt{\frac{1-\left(\frac{f_{c, 90}+\sigma_{z}}{f_{c, 90}+f_{t, 90}}\right)^{2}}{1-\left(\frac{f_{c, 90}}{f_{c, 90}+f_{t, 90}}\right)^{2}}}
$$

As shown in Fig. 4, in the case of LVL made of European beech wood, both Eqs. 15 and 16 exhibit that a tensile stress $\left(\sigma_{z}>0\right)$ has a negative influence on the shear stress. In the case studied, Eqs. 15 and 16 give nearly the same result.

In conclusion, the common aspect of all failure criteria, which can be applied, is that perpendicular tension has a negative influence on the shear strength of timber. However, the models to quantify the stresses are still rough and need further research. The design approach to be chosen finally should minimize the relevant timber stresses by choosing a

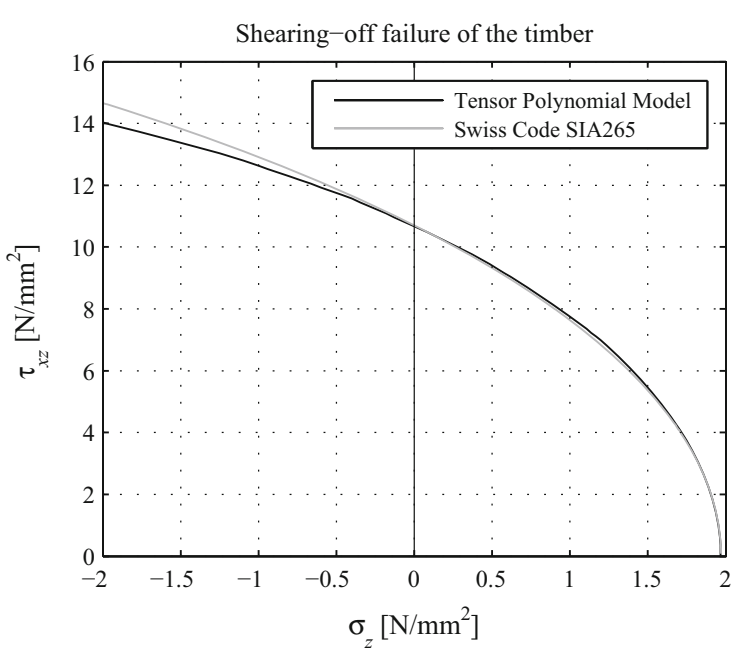

Fig. 4 Failure criteria for the combination of shear and perpendicular stress in the case of European beech LVL with the glue layers in the $x-z$-plane according to Fig. 3 (mean values of the mechanical properties: $f_{c, 90}=13.6, f_{t, 90}=1.97$, $f_{v}=10.7 \mathrm{~N} / \mathrm{mm}^{2}$ ) 
satisfying notch geometry (e.g. a sufficient length of the timber next to the notch).

\section{Shear failure of the concrete}

\subsection{Introduction}

In a timber-concrete composite member with a notched connection, the stress transfer from the concrete layer to the notch edges causes shear and tensile stresses in the concrete. The shear-carrying mechanisms in the concrete were mostly studied in the context of modeling and designing of conventional reinforced structures (e.g. [8, 28]).

The load-carrying mechanism in timber-concrete composite members with notched connections involves several analogies with conventional reinforced concrete structures. However, the most important difference is that, in a reinforced concrete member, the force is usually transferred in a continuous way along the reinforcing bars, whereas, in a timber-concrete composite member, the load transfer occurs locally through the notch edges. This aspect influences the position, the distribution and the width of the cracks.

If a conventional reinforced concrete member is provided with vertical reinforcement, after cracks develop, the vertical tensile stresses are carried by the steel reinforcement, and the composite member can be designed with stress fields and truss models [29], which ensure a predictable behavior at ultimate limit state.

In contrast, the modeling and the design of concrete members without shear reinforcement is more difficult. Several authors (e.g. [8, 30-32]) noticed that, after bending cracks develop, the load-carrying mechanism begins to change, and analyzed the various shear-carrying mechanisms. An example is the cantilever action: because of cracks, the tension zone is divided up into separate concrete elements, which can be visualized as cantilever beams fixed in the upper compression zone. All these mechanisms cause tensile stresses in the concrete near the crack tip and close to the reinforcement, which may provoke crack propagation. Nevertheless, after the propagation of a shear crack, an arching action may develop to carry the shear, which is governed by the location of the critical shear crack, its width, and the aggregate size [8]. This approach is supported by several experiments (e.g. $[33,34])$.

The geometry of timber-concrete composite members with notched connection suggests that the concrete layer carries shear by means of cantilever action.

\subsection{Simplified model for notches without reinforcement}

The present approach is based on the cantilever models for concrete structures (e.g. [30]). The composite member considered in the calculations is subjected to four-point bending, the zero-strain layer is in the concrete, and the concrete cracks grow starting from the load transfer points of the notches.

As shown in Fig. 5a, the concrete layer is modeled with a series of cantilevers delimited by the cracks, fixed in the compression zone, and subjected to the notch forces $T_{\mathrm{Ni}}$. The critical plane corresponds to the lower border of the compressive zone of the concrete $(z=c)$, and is subjected to bending and shear. The effective zone, which carries the stresses, has a length of $l_{\text {eff }}$ in $x$-direction, which is unknown and must be assumed. The shear stresses $\tau_{x z}$ are assumed to be constant over $l_{\text {eff }}$ and can be estimated as follows:

$$
\tau_{x z}=\frac{T_{\mathrm{Ni}}}{b \cdot l_{\mathrm{eff}}}
$$

The stress $\sigma_{z}$ due to the eccentricity of $T_{\mathrm{Ni}}$ is assumed to be linearly distributed over the plane, and the maximal tensile stress can be estimated as follows:

$$
\sigma_{z}=\frac{6 \cdot T_{\mathrm{Ni}}\left(h_{1}-c+\frac{t_{N}}{2}\right)}{b \cdot l_{\mathrm{eff}}^{2}}
$$

According to Fig. 5a, the most unfavorable point of the cantilever is located at the coordinates $x=0$ and $z=c$ because the tensile stress in that point is maximal. It can be assumed that, when the combination of axial and shear stress becomes critical, a crack propagates in $x$-direction, and the so called flexuralshear failure occurs. As shown in Fig. 5a, the interaction between tensile and shear stresses in unreinforced concrete can be approximated with the modified Mohr-Coulomb failure criterion [35]. To predict flexural-shear failure of concrete, the relevant part of the failure criterion is the circle BAC (Fig. 5a): 


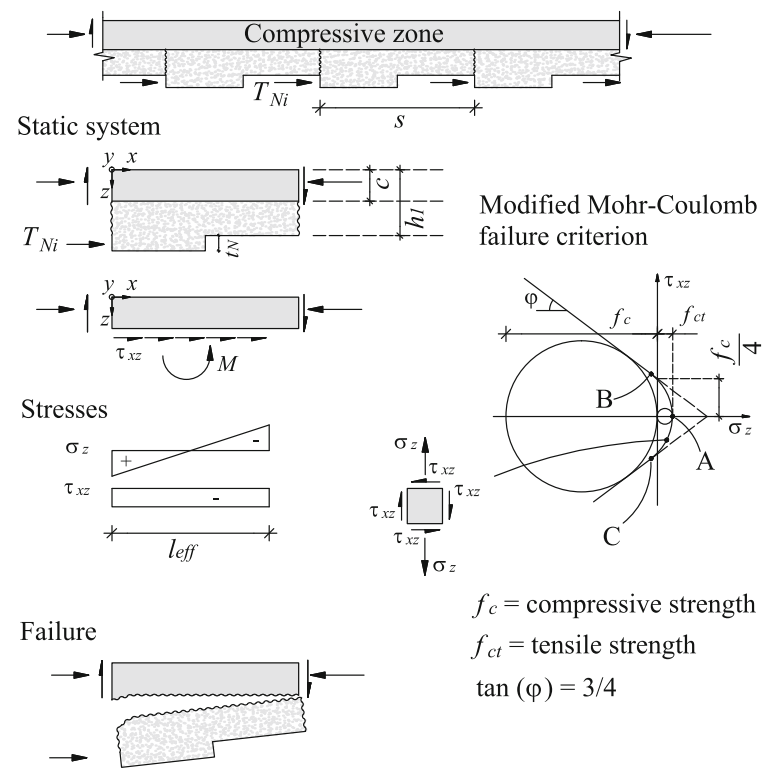

(a)

Fig. 5 Shear-carrying mechanism in the concrete part of a timber-concrete composite member with a notched connection: a model to predict flexural-shear failure of the concrete without

$$
\begin{aligned}
& \left(\sigma_{z}+\frac{f_{c}}{2}-\frac{\sin (\varphi) \cdot f_{c t}}{1-\sin (\varphi)}-f_{c t}\right)^{2}+\tau_{x z}^{2} \\
& =\left(\frac{f_{c}}{2}-\frac{\sin (\varphi) \cdot f_{c t}}{1-\sin (\varphi)}\right)^{2}
\end{aligned}
$$

The force $T_{\mathrm{Ni}}$, which causes failure of the cantilever represented in Fig. 5a, can be calculated by inserting the stresses estimated with Eqs. 17 and 18 in Eq. 19.

This model is suitable to understand the stress state of concrete and the influence of some parameters. However, a failure prediction is unsure because the model is based on the assumption of simplified crack configurations and stress distributions. A problem can be that internal stresses (which are very difficult to predict), or punching loads, may cause modifications of the crack layout as well as the growth of new cracks.

Whatever model is applied, a design of timberconcrete notched connections without vertical reinforcement may be critical because of several reasons. The crack width can become larger than in a conventional reinforced concrete structure. The fact that the position of the flexural-shear cracks in a composite member with a notched connection is usually given and corresponds to the notch edges, implies that, in contrast to conventional reinforced concrete members,

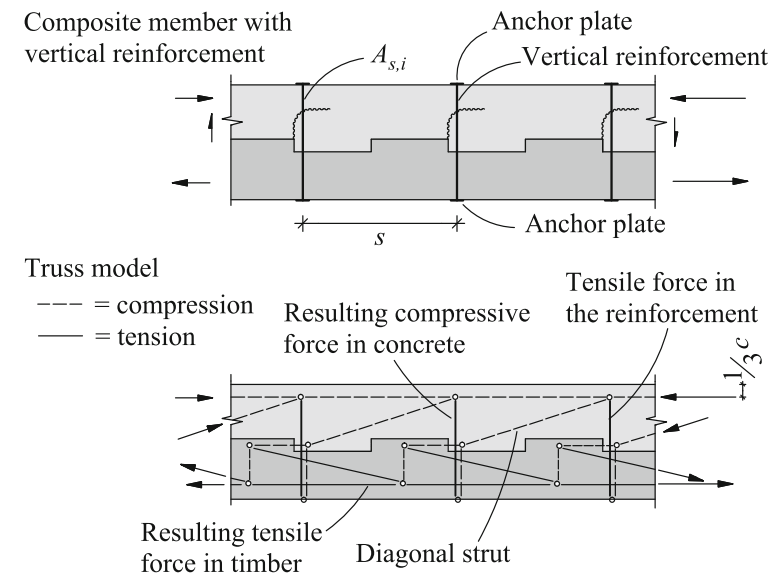

Equivalent static system for reinforcement design

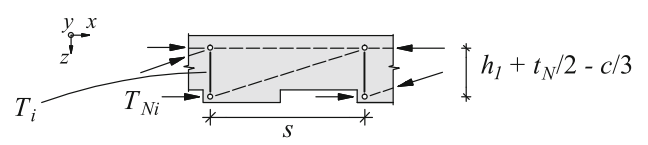

(b)

vertical reinforcement (Mohr-Coulomb failure criterion according to Marti [35]); $\mathbf{b}$ truss model for the structural behavior of a composite member with vertical reinforcement

the number of cracks is smaller and they become larger. Thus, the risk of flexural-shear failures increases because there is no interlocking action which can contribute to the shear-carrying mechanism. In addition, the fact that the concrete is stiffer than the timber, and is brittle when subjected to tension, may compromise the shear-carrying mechanism. Timber deformations within the notches, in particular when the timber develops plastic compressive deformations, may cause enlargement of the existing flexural-shear cracks in the concrete. If two notches close to each other develop different timber deformations $\left(u_{i}<u_{i-1}\right)$, the concrete cracks may enlarge, leading to an interruption of the shearcarrying mechanism.

This situation makes a reliable design without shear reinforcement more difficult than in conventional reinforced concrete structures. Because of the brittle behavior of concrete, a reliable failure prediction is not possible. The installation of vertical reinforcement is a possible solution to ensure a robust and consistent structural behavior. 
4.3 Simplified model for notches with reinforcement

As soon as a flexural-shear crack opens in the concrete, vertical reinforcement should carry the tensile stresses and prevent crack propagation. This section presents a method to design such reinforcement under the assumption that, when the vertical reinforcement activates, the load-carrying mechanism in the concrete part of the composite member approaches to a truss (Fig. 5b). The model refers to a composite member where the concrete cracks grow starting from the notch edges and the reinforcement is accomplished by means of vertical steel rods with anchorage plates on the top and bottom edge of the composite member (Fig. 5b). For different conditions (e.g. if the vertical reinforcement is made of screws), specific models can be developed using a similar procedure.

The first issue to solve is the position of the vertical reinforcement. As explained previously, the concrete layer can be divided up into a series of cantilevers fixed in the compression zone (Fig. 5a). Therefore, the impact of a vertical steel reinforcement in the notch can be compared to the effect of a longitudinal tensile reinforcement in a concrete console. Hence, the tensile reinforcement should be installed close to the notch edge where the tensile stress is maximal, so that it is able to carry the tensile stress as soon as horizontal cracks open. In the literature, other truss models can be found for timber-concrete composite members, which lead to different possible positions for the vertical reinforcement. This means that the installation of a reinforcement in a different position does not necessarily mean premature failure, but it can be that the cracks enlarge more before the reinforcement activates.

At the ultimate limit state, the presence of an adequate reinforcement in $z$-direction generates a direct bracing, which can be described by means of a truss model (Fig. 5b). The horizontal component of the diagonal concrete strut corresponds to the horizontal notch force $T_{\mathrm{Ni}}$ and is transferred to the timber part through compression in the notch edge. The vertical component of the diagonal strut is transferred to the timber thanks to compression in vertical direction, is taken by the anchorage plate on bottom edge, and is carried by the vertical reinforcement in tension.
The simplest way to estimate the tensile force carried by the vertical reinforcement is to determine, first, the horizontal notch force $T_{\mathrm{Ni}}$ according to Eq. 7 . As illustrated in Fig. 5b, the tensile force $T_{i}$ can be calculated by considering the equilibrium of the node of the truss model close to the notch $\mathrm{N}_{\mathrm{i}}$ :

$\sum F_{z}=0 \Rightarrow T_{i}=T_{\mathrm{Ni}} \cdot \frac{h_{1}+t_{N} / 2-c / 3}{s}$

The cross-section area $A_{s, i}$ of the reinforcement with yield strength $f_{y}$, which is necessary to carry the vertical tension forces $T_{i}$, can be calculated as follows:

$A_{s, i}=\frac{T_{i}}{f_{y}}=\frac{T_{\mathrm{Ni}}}{f_{y}} \cdot \frac{h_{1}+t_{N} / 2-c / 3}{s}$

However, it must be taken into account that vertical reinforcement such as screws and dowels may participate in carrying the horizontal shear flow between timber and concrete as well, thus influencing the loadcarrying mechanism [15].

\subsection{Minimum amount of reinforcement}

Reinforced concrete structures should be provided with a minimum amount of reinforcement. The most important reason is to prevent brittle failure as soon as the concrete cracks. When a crack occurs, the reinforcement should not yield. Otherwise, since the reinforcement would be in plastic conditions, it would not be able to carry the necessary tensile force, and hence, a brittle failure would occur.

For conventional reinforced concrete structures subjected to bending, analytical models to asses the minimum reinforcement are well established [36]. For vertical shear reinforcement, due to the high complexity of the shear-carrying mechanism, semi-empirical equations are used (e.g. [37]).

For timber-concrete notched connections with vertical reinforcement, the same principle should be valid. In this section, a simplified analytical model to understand the most important factors which influence the minimum vertical reinforcement is presented. It is assumed that a horizontal crack opens when the tensile stress exceeds the tensile strength of the concrete according to the cantilever model shown in Fig 5a.

Since, until the end of the elastic uncracked state, the tensile force carried by the steel is not relevant in comparison to that carried by the concrete, the 
influence of the reinforcement is neglected. Hence, the notch force $T_{N, \mathrm{cr}}$, which causes concrete cracking, can be estimated according to Fig 5a as follows:

$T_{N, \mathrm{cr}} \approx \frac{b \cdot l_{\mathrm{eff}}^{2} \cdot f_{c t}}{6 \cdot\left(h_{1}-c+t_{N} / 2\right)}$

The horizontal notch force $T_{N, y}$, which occurs when the concrete is cracked and the vertical reinforcement yields, can be estimated according to Fig. $5 \mathrm{~b}$ as follows:

$$
T_{N, y} \approx A_{s} f_{y} \cdot \frac{s}{h_{1}+t_{N} / 2-c / 3}
$$

In order to prevent brittle failure, the following condition should be satisfied:

$$
T_{N, y} \geq T_{N, \mathrm{cr}}
$$

By inserting Eqs. 22 and 23 into Eq. 24, the minimal amount of vertical reinforcement close to the notch $i$ can be calculated as follows:

$A_{s, \min } \approx \frac{b \cdot l_{\mathrm{eff}}^{2}}{6 \cdot s} \cdot \frac{h_{1}+t_{N} / 2-c / 3}{h_{1}+t_{N} / 2-c} \cdot \frac{f_{c t}}{f_{y}}$

In the presented approach, some assumptions are strongly simplified. First of all, the crack position and the effective part of the concrete, which carries the stresses, are unknown and must be assumed. Secondly, the interaction between tensile stresses in the concrete and shear stresses is neglected. In reality, as previously described by means of the Mohr-Coulomb failure criterion, shear stresses acting in the critical zone facilitate crack opening. However, in any case, a calculation neglecting the shear stresses leads to a safe design of the minimum reinforcement.

\subsection{Experimental observations}

In [14], experimental observations made during bending tests on timber-concrete composite members made of European beech laminated veneer lumber performed by Boccadoro and Frangi are described. These tests evidenced the cantilever mechanism occurring in the concrete part of the composite member, the influence of timber deformations within the notches on the concrete crack propagation and the beneficial influence of the vertical reinforcement.

During a series of preliminary four-point bending tests on LVL-concrete composite members without vertical reinforcement, flexural-shear failure of the concrete layer was observed [14]. Starting from the beginning of the test, cracks grew from the edges of the notches. This experimental observation fits with the assumption made in the model for members without reinforcement. Then, one crack propagated suddenly in longitudinal direction, causing a brittle collapse of the specimen. The observed failure put in evidence the formation of consoles subjected to bending and shear, but a good agreement between the prediction made with the cantilever model and the test result could not be found [10]. However, a quantitative comparison between model and reality is not possible yet. This would require more experimental results.

Boccadoro [10] observed that elevated timber compressive deformations within the notches influence the propagation of concrete cracks. Several LVLconcrete composite members with notched connection were designed to exhibit a ductile failure mode governed by plastic compressive deformations of the LVL in the notches and were tested in bending [10]. The specimens without vertical shear reinforcement showed that, as soon as the notches began to develop plastic deformations, some concrete cracks enlarged and propagated (Fig. 6), causing an interruption of the shear transfer in the concrete layer and thus failure of the composite member [14]. As shown in Fig. 6, the cause of the crack enlargement was the difference between the plastic compressive deformations of the LVL in the notches. Moreover, as shown in Fig. 6, this phenomenon was related to a gap opening between the enlarged cracks and the supports.

Another series of bending tests on LVL-concrete composite members with a ductile notched connection was performed with vertical reinforcement designed to carry only vertical forces. During these tests, no flexural-shear failure of the concrete occurred, and the specimen failed after large deformations due to compressive failure of the LVL in the notches [14]. It was observed that, in the parts of the composite member subjected to shear, flexural-shear cracks tended to develop, but remained closed until the end of the experiment because the vertical tension was carried by the reinforcement. In contrast, in the zone close to the mid-span, the cracks were vertical.

This mechanism showed that the reinforcement fulfilled the minimal requirements. Otherwise, a 


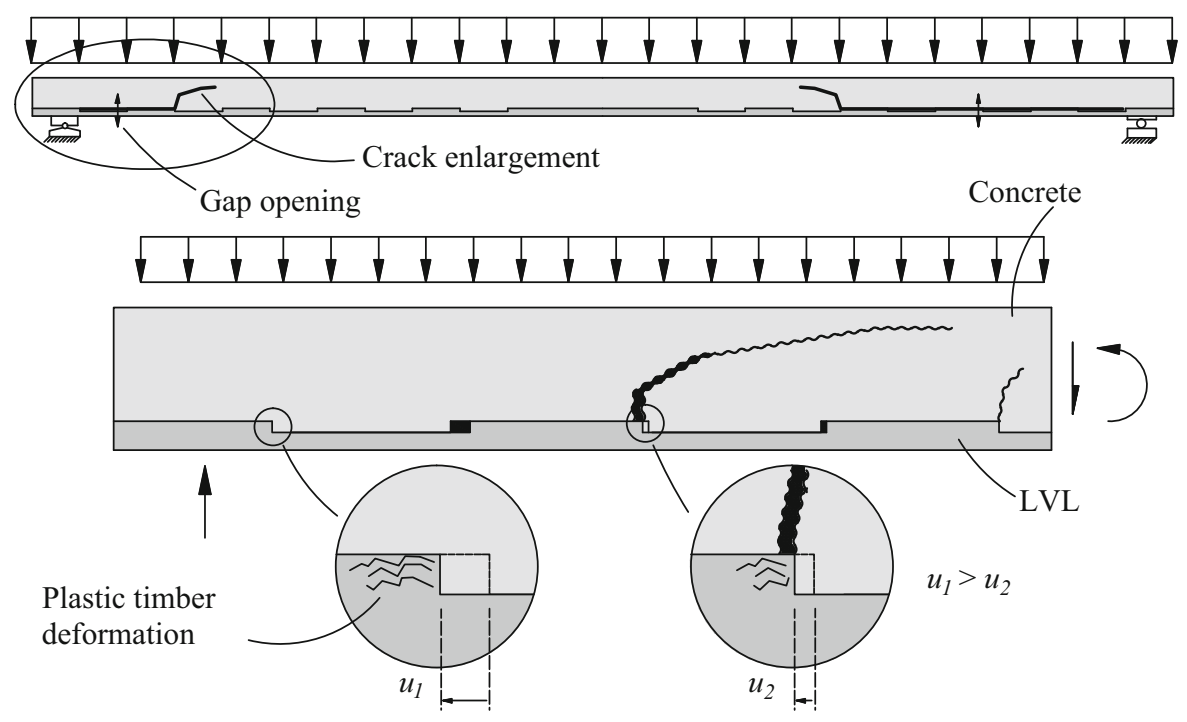

Fig. 6 LVL-concrete composite member with a ductile notched connection made of European beech wood tested with distributed vertical load: influence of plastic compressive deformations of the LVL in the notches on the propagation of cracks in concrete

sudden opening of the flexural-shear cracks would have occurred.

\section{Gap opening}

\subsection{Causes}

The vertical opening of a gap between the tensile and the compressive part of a composite member subjected to bending is an important issue because it may cause failure or increase the risk of determinate failures, and hence, should be prevented. This phenomenon is difficult to quantify because it can be due to different reasons, and the need for vertical reinforcement to prevent this problem is still being discussed. In the literature, several reasons are reported, among which:

- different deflections of the parts of the composite member due to different bending stiffness [38];

- different shear deformations of the two parts [39];

- eccentricity between the shear forces at the interface and the centroids of the parts [39].

The following analysis will concentrate on the third mechanism. Figure 7 shows a qualitative illustration of this effect in the case of a timber-concrete composite member with a notched connection without vertical reinforcement subjected to four-point

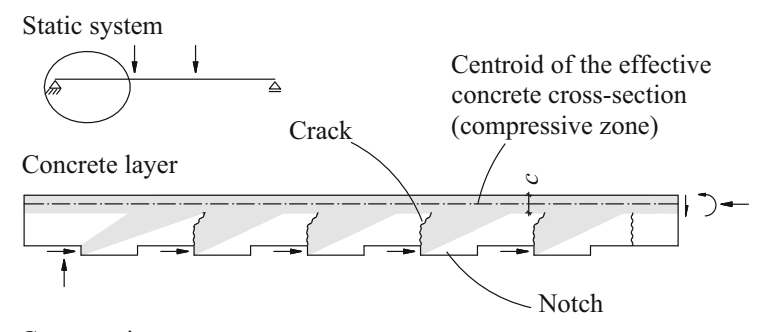

Compressive zone

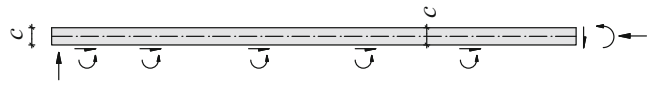

Simplified model of the compressive zone

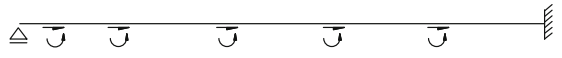

Qualitative deformation line

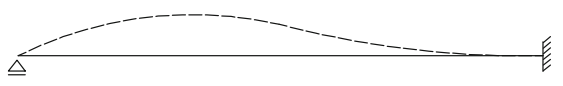

Fig. 7 Influence of the shear forces at the interface on the gap opening

bending. The notches are subjected to horizontal forces, and the concrete part of the composite member can be simplified as a compressive zone (i.e. the effective concrete cross-section) connected to cantilevers according to Fig. 5a. If the cantilevers are cut free, the lower edge of the compressive zone is subjected to bending moments, which cause a deformation of the concrete layer (Fig. 7). A similar 
mechanism occurs in the timber. Since the timber and the concrete layer are subjected to different bending moments and have different geometries and mechanical properties, they tend to develop different deformation lines, which may cause a gap opening. However, this effect is difficult to predict because it depends on the boundary conditions, the number of notches and the distance between them.

\subsection{Experimental observations}

Boccadoro and Frangi [14] observed gap opening phenomena during several bending tests on European beech LVL-concrete composite members with notched connections. Two categories of gap opening were observed: elastic gap opening (due to the mechanism shown in Fig. 7), and gap opening provoked by plastic compressive deformations of the LVL in the notches and crack propagation.

The elastic gap opening was observed especially in specimens subjected to four-point bending. Different notch geometries were tested, and the notch depth was $15 \mathrm{~mm}$. The gap opening always occurred between the vertical loads and the supports and was clearly visible, whereas the sector between the two loads did not show this tendency (Fig. 8). The relationship between the vertical load and vertical gap opening was linear (Fig. 8). Since this phenomenon occurred only in the sectors where shear forces were transferred between the two parts of the composite member, the main reason is the eccentricity between the centroids of the effective cross-sections and the interface (Fig. 7).

The design procedure of this type of LVL-concrete composite member with notched connections was optimized so that the behavior was governed by plastic

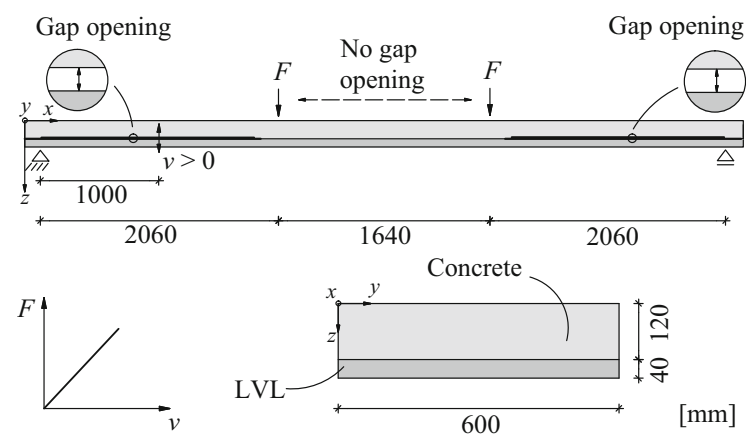

Fig. 8 Elastic gap opening observed during four-point bending tests [14] deformations of the LVL in the notches in order to develop ductility [10]. To validate the model, several specimens were tested with a uniformly distributed vertical load, and the influence of vertical reinforcement was investigated. Due to the test configuration with distributed load, the gap opening in elastic conditions was smaller than that observed in the specimens subjected to four-point bending. However, the issue of gap opening was emphasized by plastic compressive LVL failure within the notches. The specimens without vertical reinforcement, starting from the beginning of the plastic compressive deformations of the LVL within the notches, showed a marked tendency to gap opening. This phenomenon always occurred in different zones. At the same time, it was observed that some concrete cracks enlarged. These two phenomena compromised the load-carrying capacity of the specimens and determined the end of the test (e.g. Fig. 6). Some specimens were provided with vertical end-to-end reinforcement to hold the LVL and the concrete together. These reinforcements prevented gap opening and crack opening.

The marked increase of the gap opening during plastic deformations of the timber in the notches is due to several phenomena that influence themselves. Elevated plastic compressive deformations of the timber within the notches facilitated a sliding out of the concrete layer and thus caused gap opening. Moreover, isolated cracks in the concrete with large dimensions had the effect of hinges in the concrete layer, and so the concrete tended to bend in an angled way. As explained in Fig. 6, also the enlargement of the concrete cracks is influenced by the plastic deformations of the timber within the notches.

\subsection{Design of reinforcement to prevent gap opening}

Since gap opening compromises the structural behavior, the composite member should be designed to prevent this phenomenon. As observed experimentally, vertical reinforcement which connects the timber and concrete prevents gap opening. In addition, as explained previously, vertical reinforcement has a beneficial influence on the shear resistance of the concrete. Thus, the design of a vertical reinforcement which achieves both these objectives is a possible solution. 
The amount of vertical reinforcement necessary to prevent gap opening can be estimated based on the maximum deflection $w_{u}$, which the composite slab should theoretically reach. It is assumed that, at midspan, there is an enlarged crack, and consequently the concrete layer deforms in an angled $\left(\alpha_{1, u}=\arctan \left(2 w_{u} / l\right)\right)$, whereas the timber part bends as a parabola (Fig. 9). The reason for this conservative assumption is that it is very difficult to asses the length of the sector in which the gap opens.

The difference between the deformations of the two parts of the composite member can be idealized as the projection $v_{u}$ of the difference between the deflection of the timber $w_{2, u}$ and the concrete $w_{1, u}$ at $x=l / 4$ :

$v_{u}=\left(w_{2, u}-w_{1, u}\right) \cdot \cos \left(\alpha_{1, u}\right)=\frac{w_{u}}{4} \cdot \cos \left(\alpha_{1, u}\right)$

Since the bending stiffness of the concrete part is usually greater than that of the timber part, the gap $v_{u}$ can be theoretically closed by applying a vertical distributed force $q\left(v_{u}\right)$ to the timber part, which deforms it by $v_{u}$. If it is assumed that the timber part of the composite member has a hinge at the support and is fixed at mid span (Fig. 9), $q\left(v_{u}\right)$ can be estimated as follows:

$q\left(v_{u}\right)=v_{u} \cdot \frac{369}{2} \cdot \frac{E_{2} I_{2}}{(l / 2)^{4}}$

The steel reinforcement having a yield strength $f_{y}$, which is necessary to prevent gap opening, can be estimated as follows:
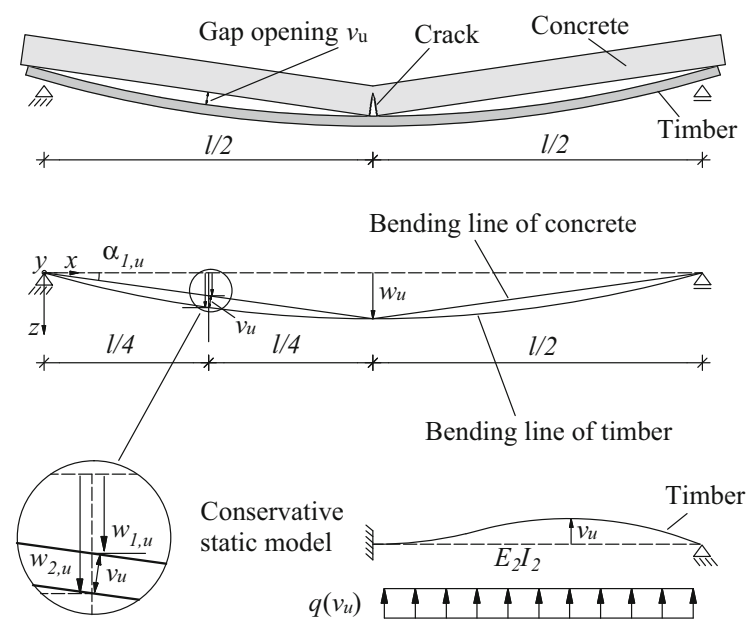

Fig. 9 Simplified model to design vertical reinforcement to prevent gap opening
$A_{s, \min , v}=\frac{q\left(v_{u}\right) \cdot l}{f_{y}}$

This calculation method is simple and conservative. However, it requires an estimation of the deflection of the composite member at the ultimate limit state.

\section{Conclusions}

The understanding of the shear-carrying mechanism is fundamental for a safe and reliable design of timberconcrete composite members with notched connections. This paper contributes to studying of the structural problems related to the shear-carrying mechanism and suggests design approaches. The following conclusions can be drawn:

- Several current design approaches show that a shearing-off failure of the timber next to the notch is facilitated by local tensile stresses. This failure should be prevented by choosing a suitable notch geometry. However, the modeling of the critical zone of the timber part needs additional research.

- The load transfer from the compressive concrete zone to the notch edge develops a cantilever action which implies combinations of shear and tensile stresses and can lead to failure. This finds agreement with experimental observations. Since this failure is influenced by several uncertain parameters, it is suggested to provide the composite member with an adequate vertical reinforcement in order to develop a controllable and robust loadcarrying mechanism.

- The vertical opening of a gap between the timber and concrete has several mechanical reasons, some of them difficult to quantify. This paper discusses the influence of shear transfer at the interface on gap opening and suggests a simplified method to design vertical reinforcement to prevent this phenomenon

Acknowledgements The Swiss National Science Foundation SNSF (NRP 66) and Climate-KIC are gratefully acknowledged for financing and supporting the project.

\section{Compliance with ethical standards}

Conflict of interest The authors declare that they have no conflict of interest. 


\section{References}

1. Deam BL, Fragiacomo M, Buchanan AH (2008) Connections for composite concrete slab and LVL flooring systems. Mater Struct 41(3):495-507

2. Van der Linden MLR (1999) Timber-concrete composite beams. HERON 44(3):215-239

3. Gutkowski RM, Brown K, Shigidi A, Natterer J (2004) Investigation of notched composite wood-concrete connections. J Struct Eng 130(10):1553-1561

4. Michelfelder BC (2006) Trag-und Verformungsverhalten von Kerven bei Brettstapel-Beton-Verbunddecken. PhD thesis, University of Stuttgart, Stuttgart

5. Boccadoro L, Frangi A (2014) Experimental analysis on the structural behavior of timber-concrete composite slabs made of beech-laminated veneer lumber. J Perform Constr Facil 28(6):A4014006

6. Blass HJ, Ehlbeck J, van der Linden M, Schlager M (1995) Trag- und Verformungsverhalten von Holz-Beton-Verbundkonstruktionen. Versuchsanstalt für Stahl, Holz und Steine, Abteilung Ingenieurholzbau Universität Fridericiana Karlsruhe, Germany

7. Schönborn F (2006) Holz-Beton-Fertigteilelemente. PhD thesis, Leopold-Franzens-Universität, Innsbruck

8. Muttoni A, Ruiz MF (2008) Shear strength of members without transverse reinforcement as function of critical shear crack width. ACI Struct J 105(2):163-172

9. Zöllig S (1999) Holz-Beton-Verbund mit vorgefertigten Brettstapel-Modulen. In: SAH-Fortbildungskurs 1999, tragende Verbundkonstruktionen mit Holz, Schweizerische Arbeitsgemeinschaft für Holzforschung

10. Boccadoro L (2016) Timber-concrete composite slabs made of beech laminated veneer lumber with notched connection. PhD thesis, ETH Zurich, Zurich

11. Frangi A, Fontana M (2003) Elasto-plastic model for timber-concrete composite beams with ductile connection. Struct Eng Int 13(1):47-57

12. Richter K, Steiger R, Frangi A, Sigrist C (2010) Dokumentation D0235 Holzbau-Ergänzende FestlegungenNorm SIA 265/1, Bauteile aus Holzwerkstoffen. Bemessungskonzept und Beispiele. Swiss Society of Engineers and Architects, Zurich

13. Steck G (1997) Euro Holzbau-Teil 1, Grundlagen. Werner Verlag, Düsseldorf

14. Boccadoro L, Frangi A (2016) Experimental investigations on timber-concrete composite slabs made of beech laminated veneer lumber with notched connection. Institute of Structural Engineering, ETH Zurich, Zurich

15. Frangi A (2001) Brandverhalten von Holz-Beton-Verbunddecken. $\mathrm{PhD}$ thesis, ETH Zurich, Zurich

16. Colling F (2008) Holzbau-Grundlagen und Bemessungshilfen, 2nd edn. Vieweg+Teubner, Wiesbaden

17. Fonrobert F (1960) Grundzüge des Holzbaues im Hochbau, 7 th edn. Verlag von Wilhelm Ernst und Sohn, Berlin

18. Smith I, Landis E, Gong M (2003) Fracture and fatigue in wood. Wiley, Chichester

19. Steurer A (2004) Grundzüge des Holzbaus-Autographie zur Vorlesung Holzbau. Institut für Baustatik und
Konstruktion, Professur für Stahl-, Holz- und Verbundbau, ETH Zürich, Zürich

20. Steiger R, Gehri E (2011) Interaction of shear stresses and stresses perpendicular to the grain. In: International council for research and innovation in building and construction. Working commission W18-timber structures, Meeting forty-four, Alghero, Paper 44-6-2

21. Wu EM (1963) Application of fracture mechanics to orthotropic plates. Tech Rep TAAM-R-248, Naval Research Laboratory, University of Illinois, Urbana

22. Gehri E (2010) Shear problems in timber engineeringanalysis and solutions. In: Proceedings of the 11th world conference on timber engineering WCTE, pp 20-24

23. Kasal B, Leichti RJ (2005) State of the art in multiaxial phenomenological failure criteria for wood members. Prog Struct Mat Eng 7(1):3-13

24. Tsai SW, Wu EM (1971) A general theory of strength for anisotropic materials. J Compos Mater 5(1):58-80

25. Van der Put, TACM (1982) A general failure criterion for wood. Tech rep, Delft University of Technology, Faculty Civil Engineering and Geosciences, Delft

26. Van der Put TACM (2009) A continuum failure criterion applicable to wood. J Wood Sci 55(5):315-322

27. Swiss Society of Engineers and Architects (SIA) (2003) SIA 265 timber structures, Zurich

28. Marti P (1999) How to treat shear in structural concrete. ACI Struct J 96(3):408-415

29. Muttoni A, Schwartz J, Thürlimann B (1997) Design of concrete structures with stress fields. Springer Science \& Business Media, Berlin

30. Kani GNJ (1964) The riddle of shear failure and its solution. ACI J 61(4):441-468

31. Fenwick RC, Pauley T (1968) Mechanism of shear resistance of concrete beams. J Struct Div 94(10):2325-2350

32. Muttoni A, Schwartz J (1991) Behavior of beams and punching in slabs without shear reinforcement. In: IABSE colloquium, vol 62. IABSE, pp 703-708

33. Leonhardt F, Walther R (1962) Shear tests on beams with and without shear reinforcement. Deutscher Ausschuss für Stahlbeton (151)

34. Muttoni A, Thürlimann B (1986) Shear tests on beams and slabs without shear reinforcement. Tech rep, Institut für Baustatik und Konstruktion, ETH Zürich, Zürich

35. Marti P (2012) Baustatik: Grundlagen, Stabtragwerke, Flächentragwerke. Ernst \& Sohn, Berlin

36. Leonhardt F, Mönnig E (1984) Vorlesungen über Massivbau-Teil 1: Grundlagen zur Bemessung im Stahlbetonbau. Springer, Berlin

37. Zilch K, Zehetmaier G (2010) Bemessung im konstruktiven Betonbau: nach DIN 1045-1 (Fassung 2008) und EN 1992-1-1 (Eurocode 2). Springer, Berlin

38. Adekola A (1968) Partial interaction between elastically connected elements of a composite beam. Int J Solids Struct 4(11):1125-1135

39. Chapman J (1964) Composite construction in steel and concrete-the behaviour of composite beams. Struct Eng 42(4):115-125 